\title{
THE APPLICATION OF THE OPTOELECTRONIC TECHNIQUE OF TRANSFERRING HEIGHTS FROM THE RECESSED BENCHMARKS IN NETWORKS IN THE EXAMINATION OF ROCK MASS DEFORMATION
}

\author{
Janusz KUCHMISTER *, Kazimierz ĆMIELEWSKI and Piotr GOŁUCH \\ Institute of Geodesy and Geoinformatics, Wroclaw University of Environmental and Life Sciences, \\ Grunwaldzka 53, 50-357 Wroclaw, Poland \\ *Corresponding author's e-mail: janusz.kuchmister@igig.up.wroc.pl
}

\section{ARTICLE INFO}

Article history

Received 20 February 2013

Accepted 12 July 2013

Available online 26 November 2013

Keywords:

Optoelectronic technique

Mono-photogrammetry

Precise levelling

\section{ABSTRACT}

The article presents a new method for transferring height from benchmarks on which the levelling staff cannot be set. The aim of transferring height is tie in measurements to the network. Reference points and control points in geodetic networks used for monitoring deformation of various objects are permanently affixed to various objects such as building walls or the ground. Changes that affect both the technical infrastructure and geological objects cause that some of these benchmarks are permanently destroyed or cannot be accessed to level them.

The first of the proposed methods is based on mono-photogrammetry and uses the Direct Linear Transformation (DLT) method. The experimental measuring set proposed to transfer height: camera (CCD / CMOS), a typical levelling staff with box level and the a designed signaling device. The signal device is mounted on the benchmark, and in its vicinity, the levelling staff is set vertically on the levelling plate. A single photo of the signal and the levelling staff was taken, and next the image was transformed by the DLT method. The height difference between the benchmark and the levelling staff foot was determined on this basis.

The second proposed method for transferring height, developed by the authors, relies on the levelled laser beam that is emitted from the benchmark towards the levelling staff. The picture of the staff graduation with the laser light spot taken with a digital camera is then processed using photogrammetry in order to find the value of the reference reading. The experimental works that had been carried out enabled to determine the accuracy of the laser reference and its range. The laboratory works discussed within this article indicate that it is possible to create height references with the accuracy of the hundredth parts of a millimetre and to accomplish the reference range up to a few metres. The presented measuring set features the small size and simple operation.

\section{INTRODUCTION}

To ensure safety of people and their property it is necessary to monitor changes that occur in the environment. It may be done using specialist equipment that performs relative and absolute measurements. In order to determine absolute vertical displacements the method of precise geometric levelling is employed (Filmer and Featherstone, 2011; Łyszkowicz and Bernatowicz, 2011; Pospíšil et. al., 2010). Controlled points that represent the object are being connected to reference benchmarks that should be located outside the object impact zone. Sometimes it happens that both controlled benchmarks and reference benchmarks are obscured, partially covered or recessed (Fig. 1) which makes it impossible to place a levelling staff on them.

The development of the optoelectronic technique (Ćmielewski, 2007;) and measuring capabilities of modern cameras encouraged the authors of this paper to design a set of devices that can be employed for the precise transfer of height from the benchmark to the levelling staff set on the working benchmark located nearby.
The set of devices and the method of measurements proposed by the authors facilitate the inclusion of these benchmarks in further levelling works. It is significant as the heights of these benchmarks constitute a salient source of data when analysing the displacements within the object (Kapłon and Cacoń, 2009; Margański et al., 2011) and the behaviour of reference benchmarks. By using these techniques of measurements it is possible to successfully incorporate the old benchmarks to the levelling network (Filmer and Featherstone, 2011). These benchmarks have been previously excluded from this network as precise levelling staff could not be set on these benchmarks correctly.

The described devices and survey method are not directly connected with the study of movements of rock blocks (such as inclinometers and distansometer), however they allow indirectly on a complete analysis of the ongoing changes in the upper lithosphere, by incorporating previously skipped levelling observation due to the unavailability of benchmark. 

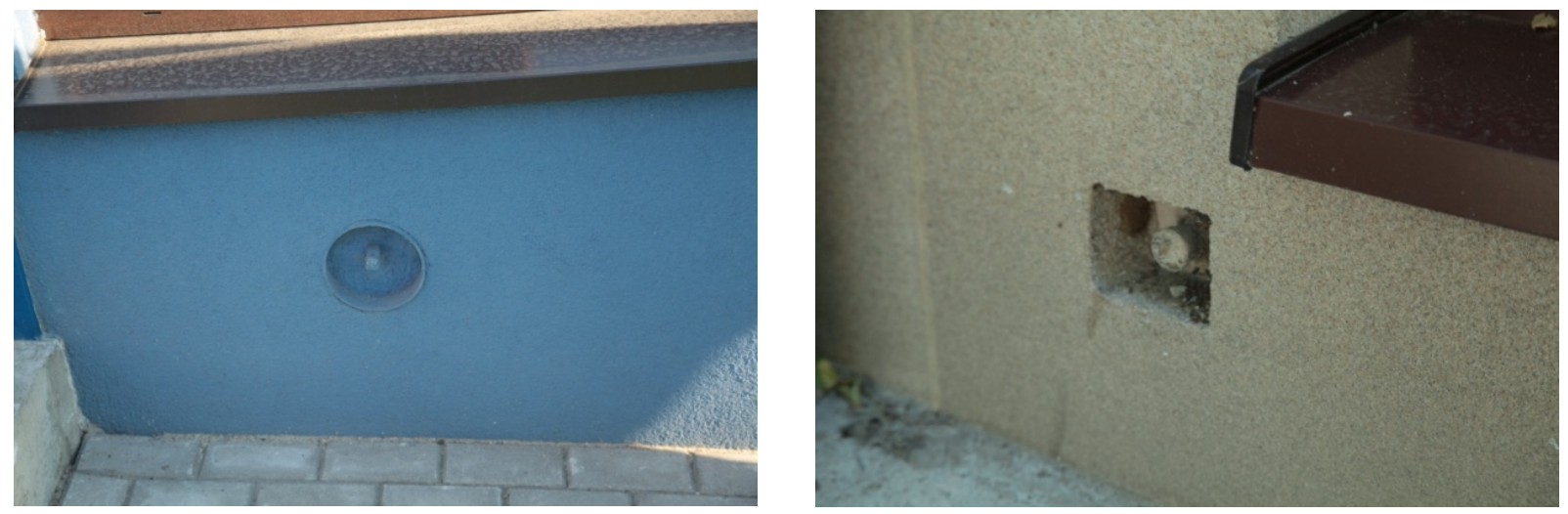

Fig. 1 Examples of benchmarks that are recessed.

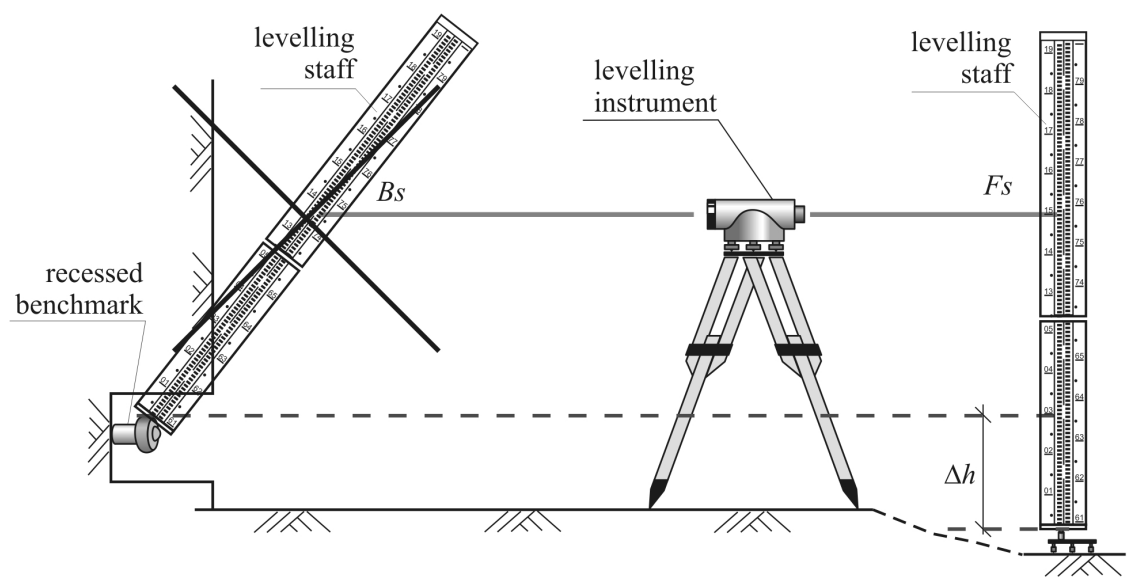

Fig. 2 The problem of setting the levelling staff on the recessed benchmark during the precise levelling.

\section{THE IDEA OF LEVELLING INACCESSIBLE BENCHMARKS USING THE PHOTOGRAM- METRIC METHOD}

When it is not feasible to set the levelling staff on the recessed benchmark, the following methods of measurement may be used:

1. trigonometric levelling;

2. mechanical structures:

(a) that are placed on the benchmark in order to set the staff;

(b) that transfer height of the benchmark on the levelling staff (e.g. rulers);

3. photogrammetric method;

(a) stereometric method;

(b) mono-photogrammetric method;

(c) method which employs the optoelectronic technique.

The application of trigonometric levelling and methods that use mechanical structures do not always ensure the satisfactory accuracy of field measurements. Field conditions may not favour their use, either. Due to this fact, the authors of this paper relying on the principles of mono-photogrammetry developed two sets of measuring devices to transfer height from the recessed benchmark to the temporary benchmark. The stereo-photogrammetric method involves the use of stereometric camera (or a picture taken from a base using a single camera).

In this article the authors have focused on the application of mono-photogrammetry and the optoelectronic technique to transfer heights.

The essence of the solution proposed by the authors is the precise transfer of height from the benchmark that is covered to the levelling staff which involves photogrammetric measurements and a special set of devices. Two variants of transferring the elevation from the benchmark to the levelling staff have been developed.

\subsection{THE IDEA OF TRANSFERRING ELEVATION USING MONO-PHOTOGRAMMETRY}

In the first scenario (Fig. 3) a target plate is attached to the benchmark during the measurements. 


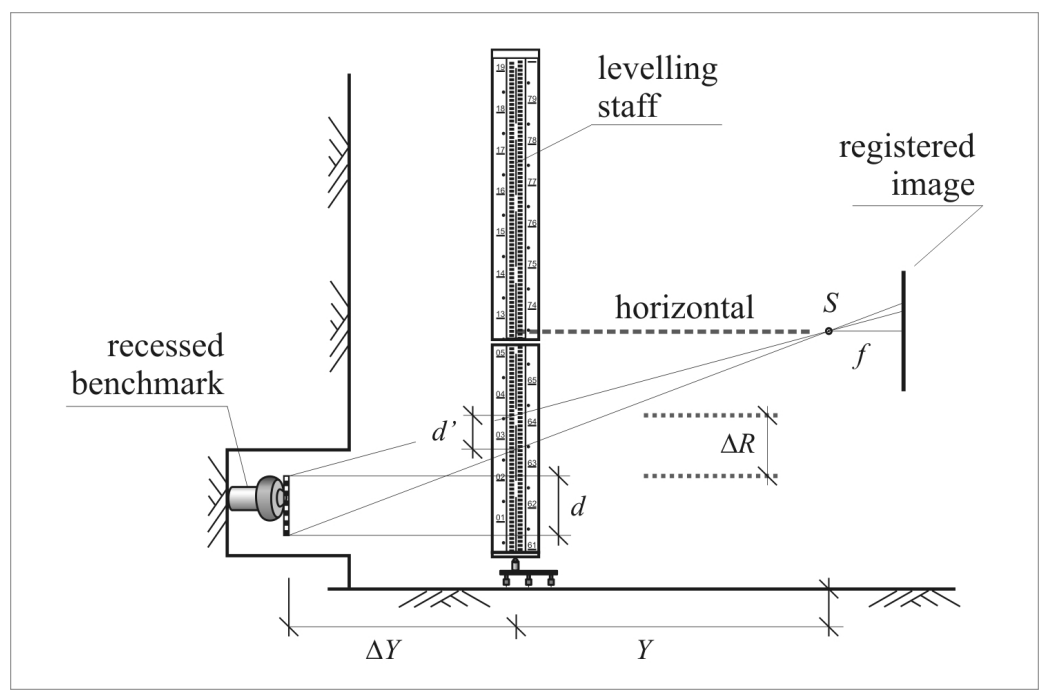

Fig. 3 The essence of transferring elevation from the benchmark to the levelling staff using the monophotogrammetry method. Symbols:

$Y$ - photographing distance between the camera station and the staff graduation

$\Delta Y$ - difference in the photographing distance between the staff graduation and the target plate;

$f$ - focal length of the camera optical system;

$S$ - centre of projection;

$d$ - the actual length of the vertical section measured on the target plate;

$d$ '- measured length of the section $\mathrm{d}$ on the image scaled according to the staff graduation;

$\Delta R$ - radial displacement resulting from the difference in distance $\Delta Y$.

In the vicinity of this benchmark a levelling staff is set on the temporary benchmark. Then the picture of the target plate and staff graduation needs to be taken with the camera. Then photogrammetric measurements are carried out on the target plate and staff graduation images. On the base of these measurement results, the difference in elevation between the benchmark that is covered and the temporary benchmark is determined.

The photogrammetric calculations rely on the Direct Linear Transformation (DLT) method. The essence of this method is:

- transformation from the image of a flat object with any orientation (unknown) to the plane with a set orientation. In our case the set plane is determined by the plane of vertically set levelling staff;

- the transferred image may be registered with the camera of unknown internal orientation, i.e. a non-metric camera.

In order to increase the accuracy of height difference being determined, at least two pictures need to be taken. Pictures can be taken hand-held or when the camera is set on a tripod. The main factors responsible for geometric distortion in a single picture are: different distances to photographed points, nonperpendicularity of the optical axis to the photographed plane and errors of the optical system of the camera (Kraus, 2007). In order to minimise the impact of geometrical distortions of the registered image on the difference in height, it is essential to point the camera towards the object that is photographed.

While taking measurements in the single image it is important to note that according to the principle of mono-photogrammetry (Kraus, 2007) scales of individual image points may be different due to the difference in the photographing distance.

The general formula for the scale of the image can be written as (1):

$\frac{1}{m}=\frac{1}{L}$

then the scale difference of two points with different photographing distances is (2):

$\Delta m=m_{t}-m$

where:

$l$ - section measured in the image;

$L$ - section measured in the field;

$m$ - image scale denominator (determined for the staff graduation photographing distance);

$m_{t}$ - image scale denominator (determined for the target plate photographing distance);

$\Delta m$ - image scale denominators difference for points with different photographing distances.

Due to the presence of a radial displacement of the target plate $\Delta R$ in the single image which is caused by the difference in photographing distance $\Delta Y$ (Fig. 4) it is necessary to calculate the scale 


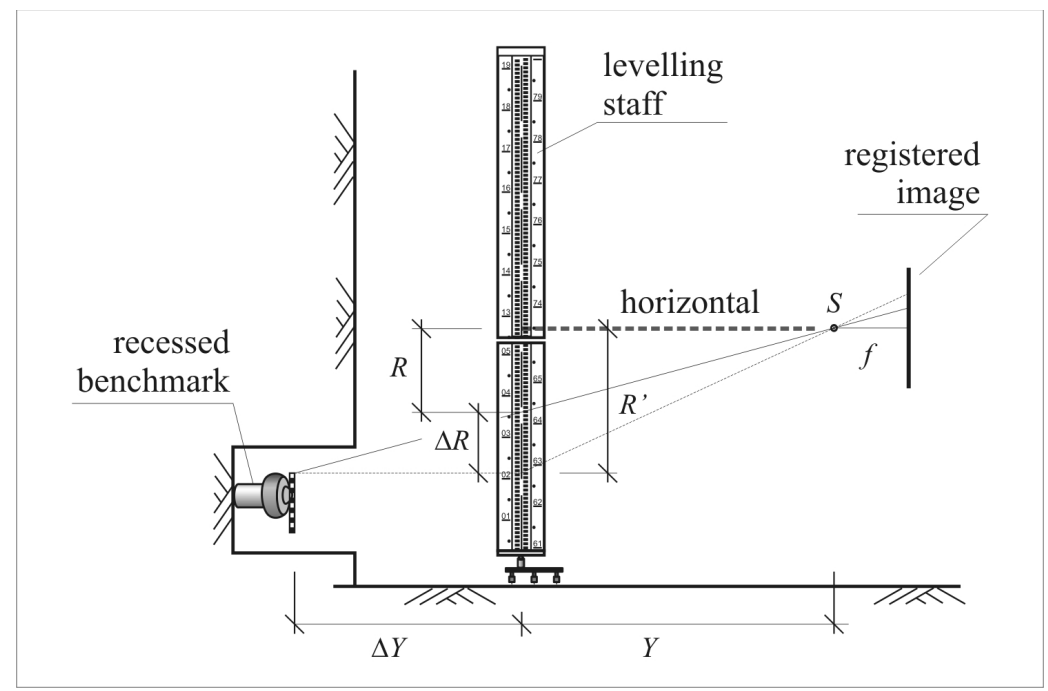

Fig. 4 The essence of radial displacement in a single image resulting from the difference in photographing distance $\Delta Y$.

denominators difference $\Delta m$ (3) and make the appropriate correction $\Delta R$ (4 and 5$)$ in the measured value $R(6)$.

$$
\frac{\Delta Y}{Y}=\frac{\Delta m}{m}
$$

$\frac{\Delta R}{R}=\frac{\Delta Y}{Y}$

$\Delta R=R \cdot \frac{\Delta m}{m}-R \cdot\left(\frac{m_{t}}{m}-1\right)$

$R^{\prime}=R+\Delta R$

where:

$\Delta Y$ - difference in the photographing distance;

$Y$ - distance between the camera station and the staff graduation;

$m$ - image scale denominator (determined for the staff graduation photographing distance);

$\Delta m$ - difference of image scale denominators for points with different photographing distances;

$R$ - vertical distance between the measured point and the image nadir point;

$\Delta R$ - radial displacement resulting from the difference in the photographing distance;

$R^{\prime}$ - adjusted vertical distance of the measured target plate point;

Photogrammetric office works (photogrammetric processing of images) typically involve the following steps:

- development of a vector model of the levelling staff graduation (staff local coordinate system);

- measurement of characteristic points of the graduation in the registered image, where the model was elaborated for these points;
- elimination of the image distortion caused by the photo inclination angle, i.e. transformation of the registered image to the vertical plane defined by the vector model of staff graduation (as a result, an equivalent/normalized image is obtained);

- measurement of the selected points of the target plate in the registered image in order to calculate the correct scale of the target plate image $1: m_{t}(1)$ (Fig. 3);

- elimination of the image distortion (the point radial displacement on the image $\Delta R$ ) caused by the difference in distance $\Delta Y$ between the target plate and the levelling staff (6) (Fig. 4).

These works were done in MicroStation v8i and using the proprietary program.

\subsection{THE IDEA OF TRANSFERRING ELEVATION USING THE PHOTOGRAMMETRIC METHOD COMBINED WITH THE OPTOELECTRONIC TECHNIQUE}

In the second variant (Fig. 5) a miniature benchmark table is installed on the benchmark. The table is equipped with the two mutually perpendicular precision glass tubular spirit levels (tubular bubbles) and a laser. In the vicinity of the benchmark a levelling staff is set on the temporary benchmark. A laser beam is levelled up using glass tubular levels is directed at the graduation of this staff. Next, the picture of the staff graduation with the laser spot image needs to be taken with the camera. Then, the energetic centre of the laser spot is detected in the registered image of the staff graduation. Principles of digital image processing are used for this purpose (Kuchmister et al., 2012). This method based on the proprietary program involves: conversion of the RGB image to the Grayscale image, and in the next steps stretching contrast, filtration, segmentation and ultimately the determination of the object features (laser spot). 


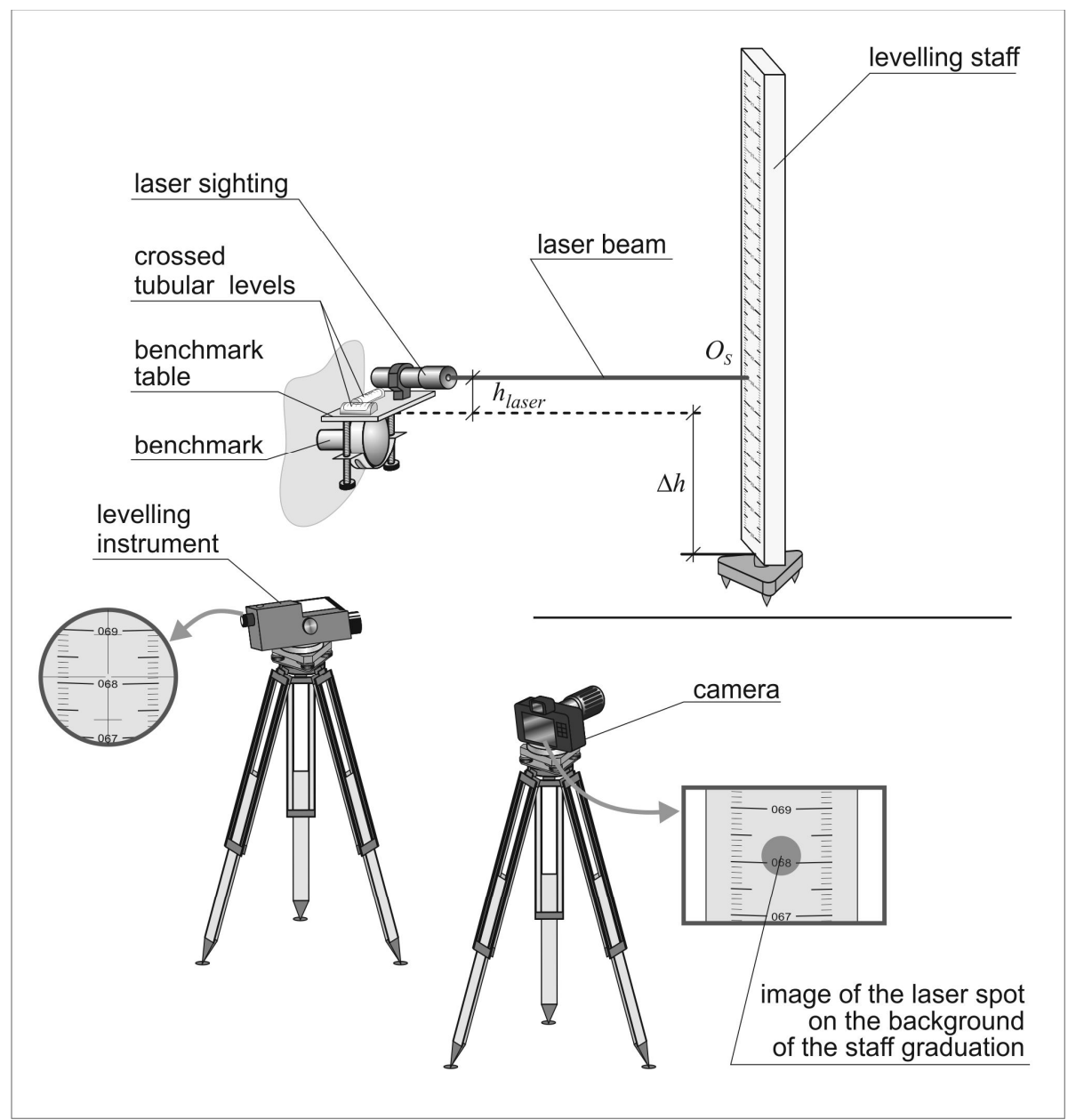

Fig. 5 The gist of transferring elevation using the photogrammetric method combined with the optoelectronic technique.

On the strength of the detected centre of the laser spot $\left(O_{s}\right)$ and the established vertical distance between the laser beam axis and the head of the benchmark $\left(h_{\text {laser }}\right)$, where the benchmark table is attached, the height difference $(\Delta h)$ between the benchmark and the temporary benchmark is determined (7) (Fig. 5).

$\Delta h=h_{\text {laser }}-O_{s}$

where:

$\Delta h$ is the height difference between the benchmark and the temporary benchmark;

$h_{\text {laser }}$ - vertical distance between the axis of a laser beam and the benchmark head;

$O_{s}$ - the result of detecting the centre of the laser spot on the staff graduation (value of photogrammetric reading).

\section{RESEARCH AND EXPERIMENTAL WORKS}

Research and experimental works were carried out in the laboratory of the Institute of Geodesy and Geoinformatics of the Wroclaw University of Environmental and Life Sciences. Pictures were taken using non-metric Canon EOS 5D Mark II camera with 24-105 mm lens. This camera was selected because of its parameters and functionality. It's a digital single- lens reflex (DSLRs) camera, where the image size is $24 \times 36 \mathrm{~mm}$ and the matrix has 21.1 million effective pixels. It was a deliberate action to disregard the internal orientation elements and to leave errors caused by the distortion of the optical system as one of the research aims was to find the accuracy of transferring height using a non-metric camera when the camera is pointed towards the staff in different ways.

To transfer heights using two measuring sets the benchmark affixed to the wall close to the laboratory base was employed. Experimental works were carried out separately for each of the methods.

\subsection{TRANSFERRING ELEVATION USING MONO- PHOTOGRAMMETRY}

The location of the measuring equipment during the research works is illustrated in Figure 6. In the preliminary research, in order to verify the conceptual assumptions of the proposed method, a staff with centimeter graduation was used, therefore, the expected error of transferring height, which depends on the picture orientation and the accuracy of staff graduation, may be $\pm 1 \mathrm{~mm}$. The accuracy can be significantly increased by using precise levelling staff 


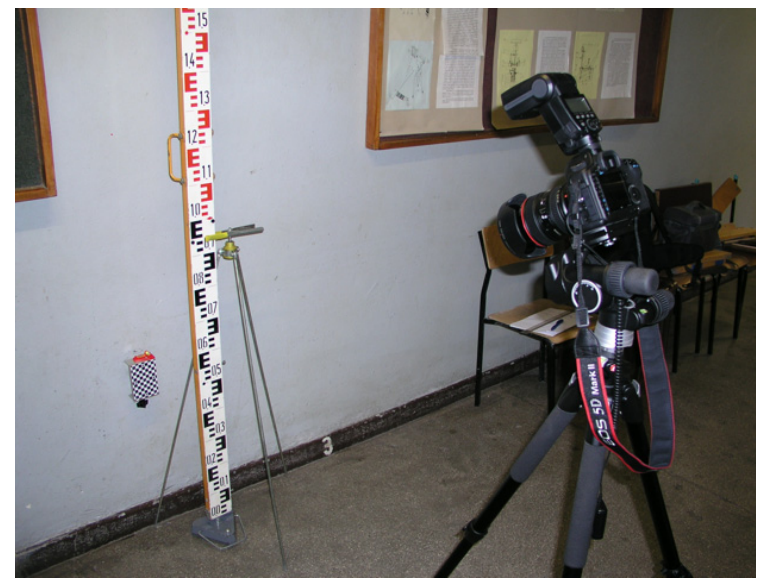

Fig. 6 The location of the measuring equipment during the research works.

equipped with snap-ins which enable to improve the accuracy of photogrammetric measurements on the registered image of the staff graduation.

The analyses relied on pictures that were taken when the camera had the following types of orientation with respect to the levelling staff (Fig. 7):

- perpendicular in the horizontal plane and the horizontal setting of the optical axis of the lens with respect to the staff (Fig. 7A);

- perpendicular in the horizontal plane and tilted setting of the optical axis of the lens with respect to the staff in the vertical plane (Fig. 7B);

- non-perpendicular in the horizontal plane and the horizontal setting of the optical axis of the lens with respect to the staff (Fig. 7C);
- non-perpendicular in the horizontal plane and tilted setting of the optical axis of the lens with respect to the staff in the vertical plane (Fig. 7B);

The experiment was conducted for different values of the focal length of the camera and for various photographing heights.

Figure 8 shows the successive stages of the photogrammetric processing of photographs. This example illustrates the photogrammetric processing with the most unfavorable photo orientation (oblique and sloped photo). On the basis of the measurements of characteristic points on the staff graduation (Fig. $8 \mathrm{~A})$ the image was converted into the previously developed vector model of the staff graduation (Fig. 8B and Fig. 8C). As a result of this process we obtain an equivalent/normalized image on which are eliminated the image distortion caused by the photo inclination angle. The final step in calculations is to eliminate distortion caused by the difference in distance between the target plate and the staff graduation. In order to do it, it is necessary to establish the location of the horizon $\left(H_{\text {cam }}\right)$. It may be done analytically (using the photogrammetric method as in Fig. 8C) or on the strength of field measurements.

After setting the staff on the temporary benchmark, the height difference between the benchmark and the temporary benchmark was determined using geometric levelling. The established difference in height was used to carry out accuracy analyses of the height differences being determined when pictures have different orientation as a consequence of using the photogrammetric method.

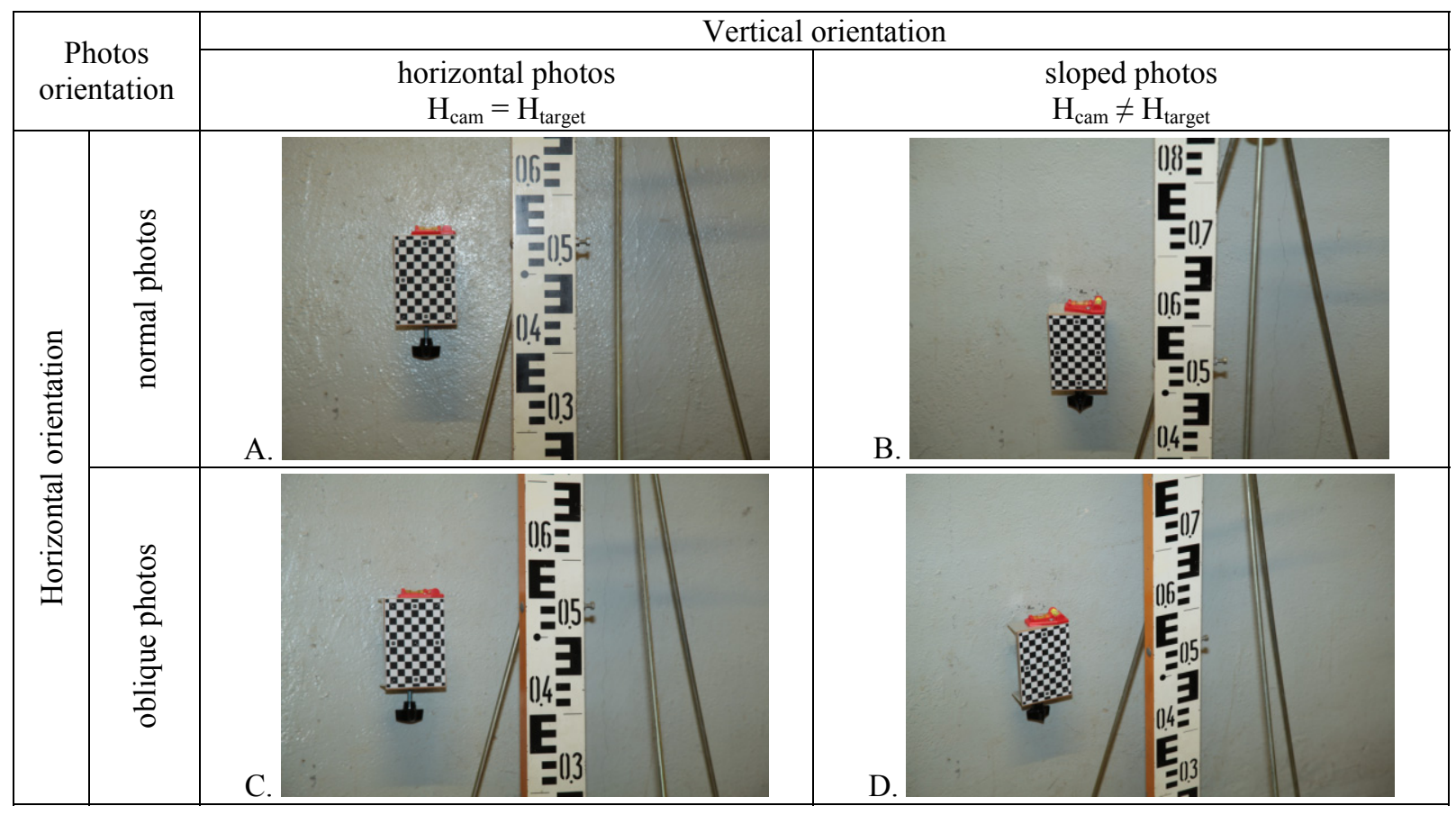

Fig. 7 Pictures selected to carrv out accuracv analvses. 


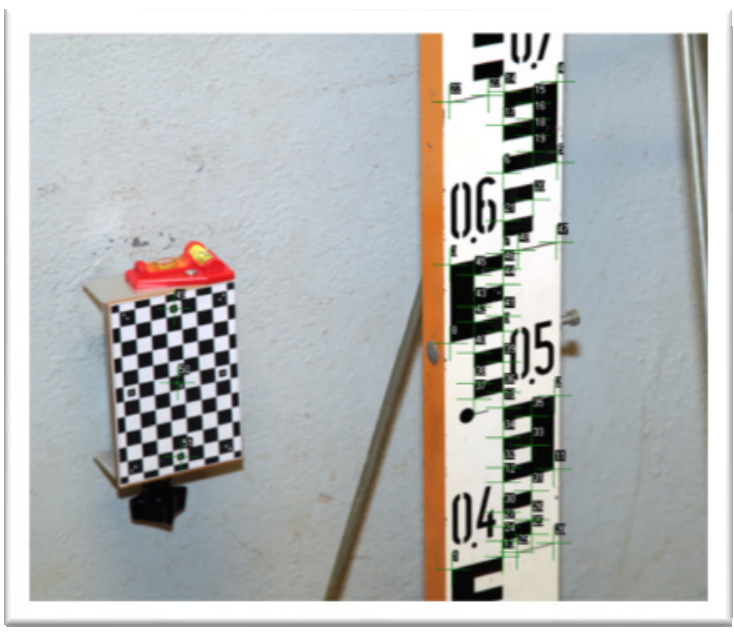

A.

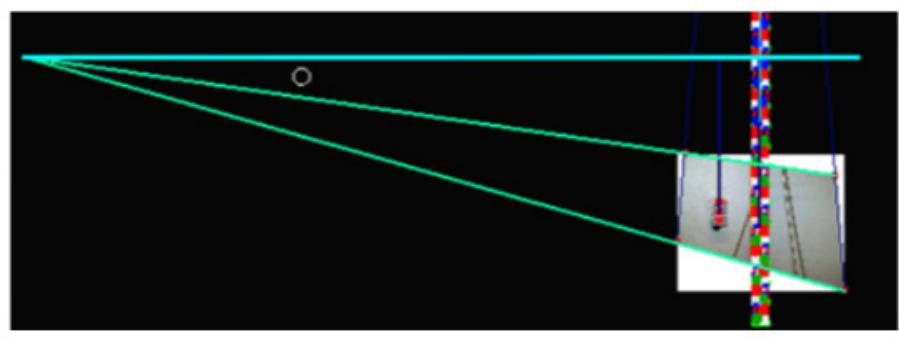

C.

Fig. 8 Stages of the photogrammetric processing of the images:

A. measurement of the characteristic points of the staff graduation;

B. image view after conversion into the vector model of the staff graduation;

C. analytical determination of the horizon.

Table 1 Summary of the results of levelling and photogrammetric measurements for different parameters of image registration and the accuracy analysis.

\begin{tabular}{|c|c|c|c|c|c|c|c|}
\hline \multirow[b]{2}{*}{$\begin{array}{c}\text { Id } \\
\text { photo }\end{array}$} & \multicolumn{2}{|c|}{$\begin{array}{c}\text { Photo's } \\
\text { orientation }\end{array}$} & \multirow{2}{*}{$\begin{array}{c}\text { Nominal } \\
\text { focal } \\
\text { length } \\
\qquad f \\
\\
{[\mathrm{~mm}]} \\
\end{array}$} & \multicolumn{2}{|c|}{$\begin{array}{c}\text { The height difference between } \\
\text { the benchmark and } \\
\text { the temporary benchmark }\end{array}$} & \multirow{2}{*}{$\begin{array}{l}\text { Differences } \\
\Delta h_{p h o t o}-\Delta h_{l} \\
{[\mathrm{~mm}]}\end{array}$} & \multirow{2}{*}{$\begin{array}{c}\begin{array}{c}\text { Standard } \\
\text { deviation } \\
S\end{array} \\
{[\mathrm{~mm}]}\end{array}$} \\
\hline & Vertical & Horizontal & & $\begin{array}{c}\text { Levelling } \\
\qquad h_{l} \\
{[\mathrm{~mm}]} \\
\end{array}$ & $\begin{array}{c}\text { Photogrammetric } \\
\text { measurements } \\
\Delta h_{\text {photo }} \\
{[\mathrm{mm}]} \\
\end{array}$ & & \\
\hline 1005 & $\begin{array}{l}\text { horizontal } \\
\text { photo }\end{array}$ & $\begin{array}{c}\text { normal } \\
\text { photo }\end{array}$ & 24 & \multirow{4}{*}{-493.6} & -494.43 & 0.83 & \multirow{4}{*}{ \pm 0.92} \\
\hline 1006 & $\begin{array}{c}\text { horizontal } \\
\text { photo }\end{array}$ & normal photo & 105 & & -493.59 & -0.01 & \\
\hline 1013 & $\frac{\text { sloped }}{\text { photo } \sim 25}^{\circ}$ & $\begin{array}{l}\text { oblique } \\
\text { photo }\end{array}$ & 105 & & -492.61 & -0.99 & \\
\hline 1017 & $\begin{array}{c}\text { sloped } \\
\text { photo } \sim 25^{\circ}\end{array}$ & $\begin{array}{l}\text { normal } \\
\text { photos }\end{array}$ & 105 & & -494.54 & 0.94 & \\
\hline
\end{tabular}

Table 1 summarizes the results of levelling and photogrammetric measurements for different parameters of image registration and the accuracy analysis.

Research works that have been carried out indicate that the standard deviation of height difference determination using mono-photogrammetry and the levelling staff with $10 \mathrm{~mm}$ graduation does not exceed $\pm 1 \mathrm{~mm}$. With the appropriate image parameters (Table 1, photo 1006) the value of error can be significantly reduced up to the hundredths of a millimeter. 


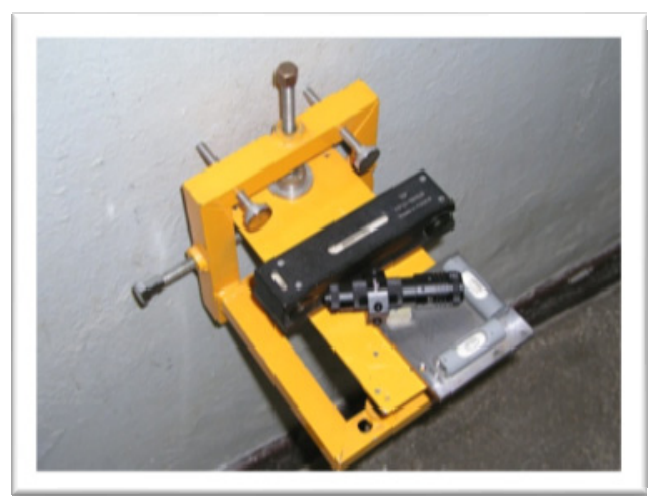

Fig. 9 The view of the benchmark table while calibrating tubular levels using the wall mounting bracket and precise machine tubular level.

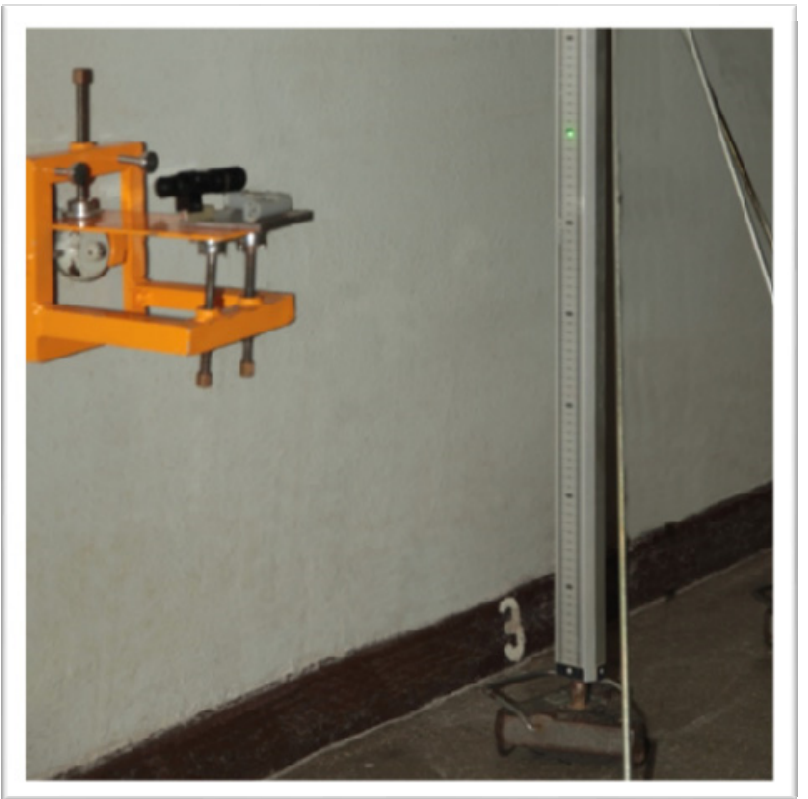

Fig. 10 The location of measuring equipment during the laser transmitter calibration.

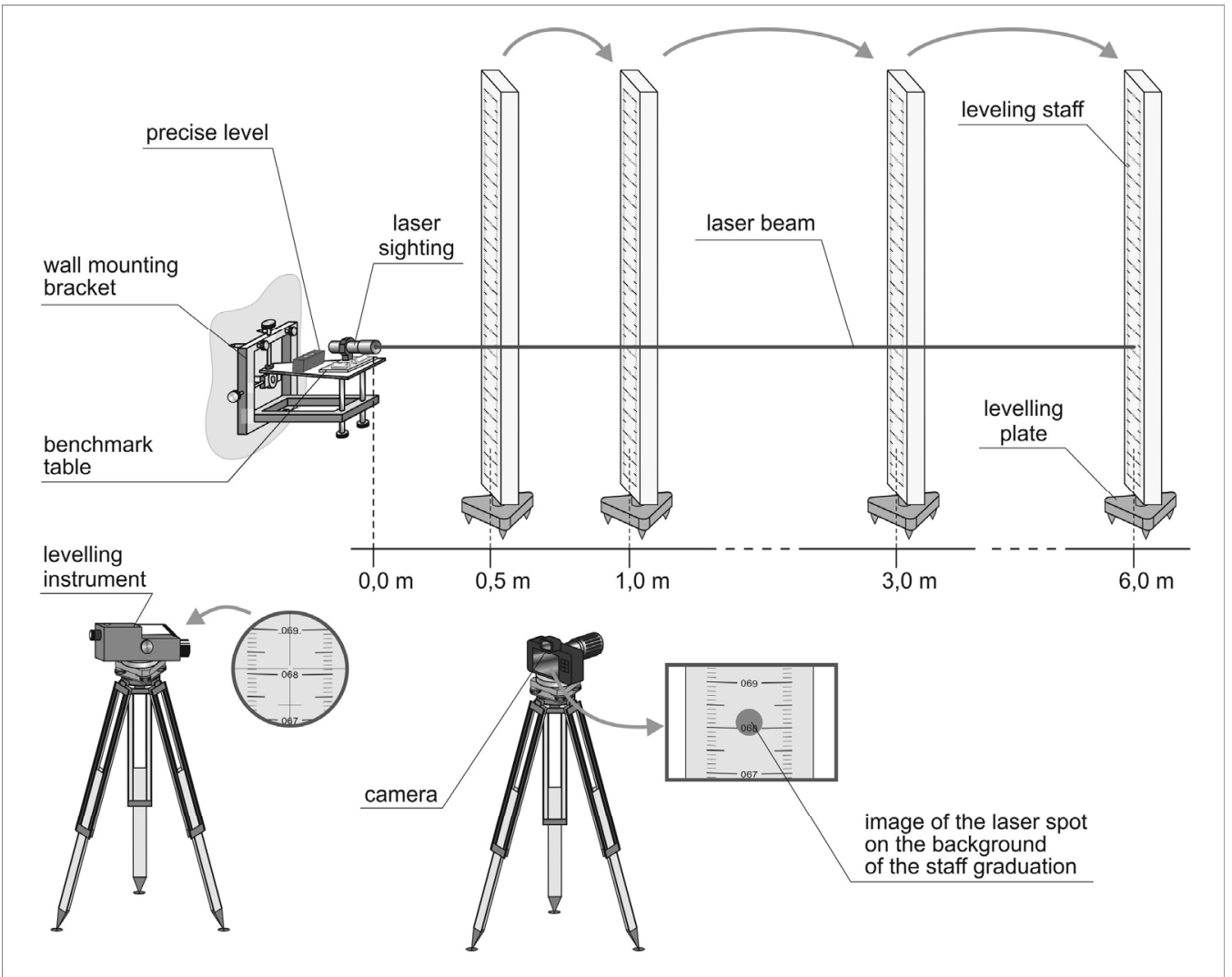

Fig. 11 The gist of calibrating the laser transmitter.

\subsection{TRANSFERRING HEIGHT USING PHOTOGRAMMETRIC METHOD COMBINED WITH THE OPTOELECTRONIC TECHNIQUE}

Before starting the actual measurements, the benchmark table was calibrated (Fig. 9). The purpose of calibration was to make the axes of tubular levels parallel to the axis of the laser beam. The calibration was done using the wall mounting bracket that are fixed to the benchmark (Fig. 10). Tubular levels of the table were checked and adjusted using the precise machine tubular level (Fig. 9). The next step after adjusting the tubular levels was to check whether the laser beam emitted by a laser transmitter was correctly set.

The gist of calibrating the laser transmitter is presented in Figure 11.

In order to correctly transfer height using the laser beam, the laser beam needs to be set horizontally 
Table 2 The results of measurements obtained during the calibration of the laser transmitter.

\begin{tabular}{|c|c|c|c|c|c|c|c|c|c|}
\hline \multirow{3}{*}{ Id Point } & \multirow{3}{*}{ 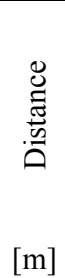 } & \multicolumn{3}{|c|}{ Geometric levelling } & \multicolumn{2}{|c|}{ Photogrammetric survey } & \multicolumn{3}{|c|}{$\begin{array}{l}\text { The height of the laser beam } \\
h_{\text {laser }}\end{array}$} \\
\hline & & $\begin{array}{c}\text { Benchmark } \\
B_{s}\end{array}$ & $\begin{array}{c}\text { Mean } \\
F_{s}\end{array}$ & $\Delta h_{l}=B_{s}-F_{s}$ & $\begin{array}{c}\text { Reading } \\
O_{S}\end{array}$ & $\begin{array}{c}\text { Adjusted } \\
\text { position } \\
O_{\text {photo }}=O_{S}-t\end{array}$ & $\begin{array}{c}\text { Value } \\
\Delta h_{l}+O_{\text {photo }}\end{array}$ & \multirow{2}{*}{$\begin{array}{c}\text { Mean } \\
\text { (final } \\
\text { value) } \\
{[\mathrm{mm}]}\end{array}$} & $\begin{array}{c}\text { Standard } \\
\text { deviation } \\
S\end{array}$ \\
\hline & & {$[\mathrm{mm}]$} & {$[\mathrm{mm}]$} & {$[\mathrm{mm}]$} & {$[\mathrm{mm}]$} & {$[\mathrm{mm}]$} & {$[\mathrm{mm}]$} & & {$[\mathrm{mm}]$} \\
\hline \multirow{4}{*}{$\begin{array}{l}\text { levelling } \\
\text { plate } 1 \\
\text { levelling } \\
\text { plate } 2 \\
\text { levelling } \\
\text { plate } 3 \\
\text { levelling } \\
\text { plate } 4\end{array}$} & 0.5 & \multirow{4}{*}{384.40} & 938.20 & -553.80 & 597.67 & 593.12 & 39.32 & \multirow{4}{*}{39.35} & \multirow{4}{*}{$\pm \mathbf{0 . 0 5 0}$} \\
\hline & 1.0 & & 941.45 & -557.05 & 600.94 & 596.39 & 39.34 & & \\
\hline & 3.0 & & 935.35 & -550.95 & 594.92 & 590.37 & 39.42 & & \\
\hline & 6.0 & & 929.65 & -545.25 & 589.12 & 584.57 & 39.32 & & \\
\hline
\end{tabular}

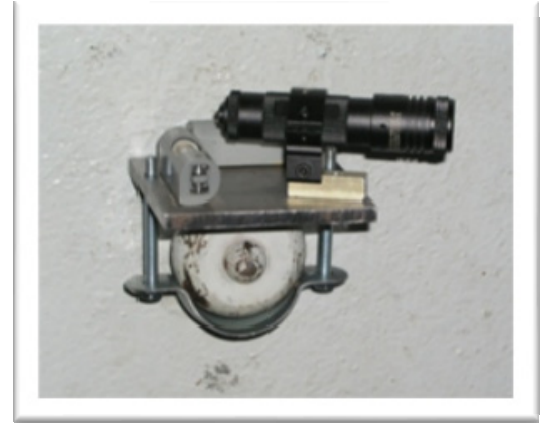

Fig. 12 The view of the benchmark table after fixing it to the wall benchmark.

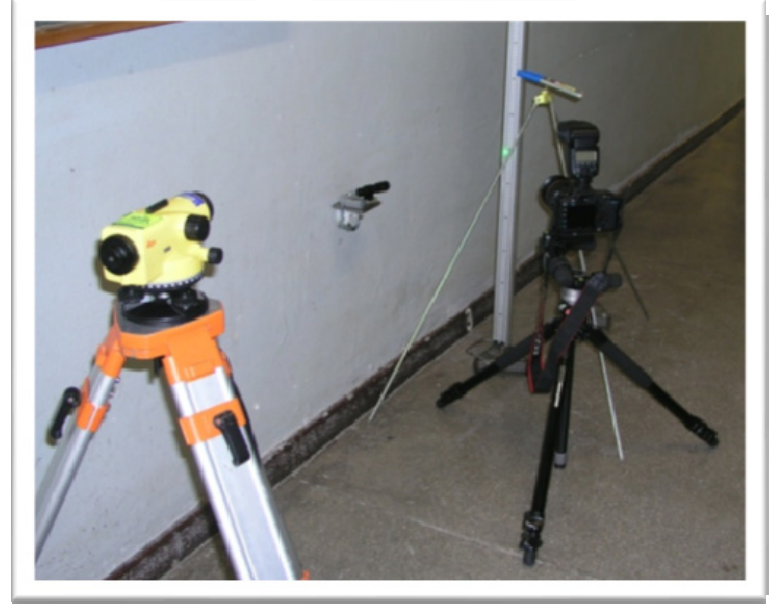

Fig. 13 The location of measuring equipment during the actual experimental works.

after levelling the tubular levels of the benchmark table. To meet this requirement, four levelling plates were located along the straight line in the following distances: $0.5 \mathrm{~m}, 1.0 \mathrm{~m}, 3.0 \mathrm{~m}$ i $6.0 \mathrm{~m}$ (Fig. 11). The heights of the levelling plate bolts were determined locally using the level and the staff with the millimetre graduation. Then, the laser was switched on and the height of levelling plates was determined. On the strength of differences in heights, the laser was adjusted.

After adjusting the benchmark table, the actual research works started. After fixing the benchmark table to the benchmark (Fig. 12) the laser beam is directed at levelling plates. The levelling staff is set on the bolts of levelling plates in such a way that the laser spot can be seen on the staff graduation. After taking a picture of the staff graduation with a laser spot and taking a reading with the level, the staff is moved to the subsequent survey points. Figure 13 presents the distribution of measuring equipment.
Levelling was done in order to compare the results of levelling with the results of photogrammetric measurements. Levelling was done in two directions: in the forward direction and then in the backward (opposite) direction. During the work special attention was paid to the right quality of the photographed image. For each setting of the levelling staff between two and seven pictures were taken in order to determine the accuracy of measurements repeatability (Table 3). On the basis of registered images and using digital methods of image analysis, the position of the energetic centre of the laser spot with respect to the staff graduation was established.

During calibration of laser transmitter, on the basis of formula (7), the distance $\left(h_{\text {laser }}\right)$ between the laser beam and the bottom surface of benchmark table (Fig. 5) was designated. Table 2 shows the results of the measurements. The plate thickness of the wall mounting bracket $(t=4.55 \mathrm{~mm})$ was included in the calculation the adjusted position of the centre of the 
Table 3 Data illustrating the location of the laser beam and the evaluation of the accuracy of photogrammetric measurements repeatability.

\begin{tabular}{|c|c|c|c|c|c|c|}
\hline $\begin{array}{c}\text { Id } \\
\text { Point }\end{array}$ & {$[\mathrm{m}]$} & Id Photo & $\begin{array}{l}\text { Value of } \\
\text { photogrammetric } \\
\text { reading } \\
{[\mathrm{mm}]}\end{array}$ & {$[\mathrm{mm}]$} & $\begin{array}{c}\text { Differences of the } \\
\text { values from their } \\
\text { mean value } \\
v \\
{[\mathrm{~mm}]}\end{array}$ & $\begin{array}{c}\text { Standard } \\
\text { deviation } \\
\qquad S_{i} \\
\\
{[\mathrm{~mm}]}\end{array}$ \\
\hline \multicolumn{7}{|c|}{ Equipment adjustment } \\
\hline $\begin{array}{c}\text { levelling } \\
\text { plate } 1\end{array}$ & 0.5 & $\begin{array}{l}1805 \\
1806 \\
1807\end{array}$ & $\begin{array}{l}597.64 \\
597.71 \\
597.66\end{array}$ & 597.67 & $\begin{array}{r}-0.03 \\
0.04 \\
-0.01\end{array}$ & \pm 0.04 \\
\hline $\begin{array}{c}\text { levelling } \\
\text { plate } 2\end{array}$ & 1.0 & $\begin{array}{l}1785 \\
1787 \\
1802 \\
1803 \\
1804 \\
\end{array}$ & $\begin{array}{l}600.87 \\
600.86 \\
600.99 \\
601.00 \\
600.99 \\
\end{array}$ & 600.94 & $\begin{array}{r}-0.07 \\
-0.08 \\
0.05 \\
0.06 \\
0.05 \\
\end{array}$ & \pm 0.07 \\
\hline $\begin{array}{c}\text { levelling } \\
\text { plate } 3\end{array}$ & 3.0 & $\begin{array}{l}1790 \\
1791 \\
1798 \\
1799 \\
1800 \\
1801\end{array}$ & $\begin{array}{l}594.88 \\
594.81 \\
594.98 \\
595.00 \\
594.91 \\
594.96\end{array}$ & 594.92 & $\begin{array}{r}-0.04 \\
-0.11 \\
0.06 \\
0.06 \\
-0.01 \\
0.03\end{array}$ & \pm 0.07 \\
\hline $\begin{array}{l}\text { levelling } \\
\text { plate } 4\end{array}$ & 6.0 & $\begin{array}{l}1792 \\
1793 \\
1793 \\
1794 \\
1795 \\
1796 \\
1797 \\
\end{array}$ & $\begin{array}{l}589.08 \\
589.09 \\
589.14 \\
589.12 \\
589.12 \\
589.18 \\
589.10 \\
\end{array}$ & 589.12 & $\begin{array}{r}-0.03 \\
-0.03 \\
0.02 \\
0.00 \\
0.00 \\
0.06 \\
-0.02 \\
\end{array}$ & \pm 0.03 \\
\hline \multicolumn{7}{|c|}{ Surveying } \\
\hline Point 1 & 0.47 & $\begin{array}{l}1808 \\
1809 \\
1810 \\
1811 \\
1816 \\
\end{array}$ & $\begin{array}{l}593.04 \\
593.03 \\
592.99 \\
593.12 \\
593.13 \\
\end{array}$ & 593.06 & $\begin{array}{r}-0.02 \\
-0.04 \\
-0.07 \\
0.06 \\
0.07 \\
\end{array}$ & \pm 0.06 \\
\hline Point 2 & 0.93 & $\begin{array}{l}1817 \\
1818\end{array}$ & $\begin{array}{l}595.66 \\
595.55\end{array}$ & 595.60 & $\begin{array}{r}0.05 \\
-0.05\end{array}$ & \pm 0.07 \\
\hline & (the ac & $\begin{array}{r}\text { Global } \\
\text { cy of phot }\end{array}$ & $\begin{array}{l}\text { idard deviation } S \text { [ } \\
\text { mmetric measuren }\end{array}$ & $\begin{array}{l}\mathrm{nm}] \\
\text { ents repeatab }\end{array}$ & & \pm 0.05 \\
\hline
\end{tabular}

laser spot $\left(O_{\text {photo }}\right)$. This is correction of the photogrammetric reading. The obtained final value of the distance between the laser beam and the bottom surface benchmark table $\left(h_{\text {laser }}\right)$ is $39.35 \pm 0.05 \mathrm{~mm}$.

Table 3 presents the results of photogrammetric measurements of the laser beam position and the evaluation of their repeatability accuracy. These are the results obtained in two stages: equipment adjustment and surveying.

The evaluation of the accuracy of photogrammetric measurements was also done by comparing height differences determined using the photogrammetric method and geometric levelling. The outcomes of measurements and calculations for two transfers of heights are presented in Table 4.

The accuracy analysis that investigates the repeatability of measurements results and the comparison of the photogrammetric method and geometric levelling indicate that the standard deviation of photogrammetric measurements is $\pm 0.05 \mathrm{~mm}$.

\section{SUMMARY}

The authors developed and created two sets of measuring devices that enable the precise transfer of height from the obscure benchmark (the recessed benchmark) using the photogrammetric method. The first concept of the height transfer relies on the DLT method, while the aim of the second one is to determine the location of the energetic centre of the laser beam through digital image processing.

The research and experimental works as well as accuracy analyses for the two variants of the height transfer lead to the following conclusions: 
Table 4 Comparison of height differences determined on the basis of the photogrammetric method and geometric levelling.

\begin{tabular}{|c|c|c|c|c|c|c|c|c|}
\hline \multicolumn{9}{|c|}{ Surveying } \\
\hline \multirow[b]{2}{*}{$\begin{array}{c}\text { Id } \\
\text { Point }\end{array}$} & \multirow[b]{2}{*}{ 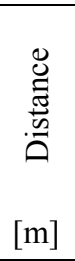 } & \multicolumn{3}{|c|}{ Geometric levelling } & \multicolumn{3}{|c|}{ Photogrammetric survey } & \multirow[b]{2}{*}{$\begin{array}{c}\text { Differences } \\
v=\Delta h_{f}-\Delta h_{l} \\
\\
{[\mathrm{~mm}]}\end{array}$} \\
\hline & & $\begin{array}{c}\text { Benchmark } \\
B_{s} \\
{[\mathrm{~mm}]}\end{array}$ & $\begin{array}{c}\text { Levelling } \\
\text { plate } \\
F_{s} \\
{[\mathrm{~mm}]}\end{array}$ & $\begin{array}{c}\Delta h_{l}=B_{s}-F_{s} \\
{[\mathrm{~mm}]}\end{array}$ & $\begin{array}{c}\text { The height of } \\
\text { the laser beam } \\
h_{\text {laser }} \\
{[\mathrm{mm}]}\end{array}$ & $\begin{array}{c}\text { Reading } \\
O_{S} \\
\\
{[\mathrm{~mm}]}\end{array}$ & $\Delta h_{f}=h_{\text {laser }}-O_{S}$ & \\
\hline Point 1 & 0.47 & \multirow{2}{*}{384.40} & 938.10 & -553.70 & \multirow{2}{*}{39.35} & 593.06 & -553.71 & 0.01 \\
\hline Point 2 & 0.93 & & 940.60 & -556.20 & & 595.60 & -556.25 & 0.05 \\
\hline
\end{tabular}

1. the advantage of the discussed methods is the use of small and lightweight equipment;

2. the preliminary works that have been carried out indicate that the projective transformation method and the laser method enabled to transfer the height from the benchmark to the levelling staff with respective accuracies of about $\pm 1 \mathrm{~mm}$ and $\pm 0.05 \mathrm{~mm}$ (submillimetre accuracies);

3. appropriately adjusted photographing parameters while taking pictures (large scale of pictures, pictures taken with the horizontal optical axis on the benchmark elevation and pictures taken perpendicularly to the staff graduation) the accuracy of photogrammetric measurements may be significantly increased up to hundredth parts of a millimetre;

4. the solutions proposed in the developed measuring sets enable to include those benchmarks in levelling that are not accessible for standard measurements.

\section{REFERENCES}

Ćmielewski, K.: 2007, Fibre optics and laser technology in high precision measurements of shapes and deformations of engineering objects. Zeszyty Naukowe UP we Wrocławiu Nr 551, seria Rozprawy CCXLVI, Wrocław, 242 pp., (in Polish).

Filmer, M. and Featherstone, W.: 2011, Error propagation for three common height-system corrections to differential leveling. Journal of Spatial Science, 56, No. 1, 39-58. DOI: 10.1080/14498596.2011.567410

Kapłon, J. and Cacoń, S.: 2009, Research on the marginal Sudetic fault activity with use of GPS and precise leveling techniques. Acta Geodyn. Geomater., 6, No. 3 (155), 323-329.

Kraus, K.: 2007, Photogrammetry, geometry from images and laser scans. Walter de Gruyter GmbH \& co. KG, 10785 Berlin, Germany.
Kuchmister, J., Ćmielewski, K., Gołuch, P. and Kowalski, K.: 2012, Application of the laser plummet to measure the linearity of elongated objects (in Polish). Acta Sci. Pol. Geod. Descr. Terr., 11 (1), 5-16.

Łyszkowicz, A. and Bernatowicz, A.: 2011, Statistical analysis of the fourth precise levelling campaign in Poland. Techn. Sc., No 14(2), 263-278.

Margański, S., Wierzbicki, E. and Olszak, T.: 2011, Investigations of vertical movements in Warsaw and surrounding regions (in Polish). Acta Sci. Pol. Geod. Descr. Terr. 10(4), 5-20.

Pospíšil, L., Švábenský, O., Weigel, J. and Witiska, M.: 2010, Geological constraints on the GPS and precise levelling measurements along the Diendorf-Čebín Tectonic Zone. Acta Geodyn. Geomater., 7, No. 3, 317-333. 